\title{
Sixth International Symposium on Bifurcations and Instabilities in Fluid Dynamics (BIFD2015)
}

Foreword

Bar-Yoseph, P. Z.; Brøns, Morten; Gelfgat, A.; Oron, A.; Tuckerman, L. S.; Wesfreid, J. E.

Published in:

Fluid Dynamics Research

Link to article, DOI:

10.1088/0169-5983/48/6/061001

Publication date:

2016

Document Version

Peer reviewed version

Link back to DTU Orbit

Citation (APA):

Bar-Yoseph, P. Z., Brøns, M., Gelfgat, A., Oron, A., Tuckerman, L. S., \& Wesfreid, J. E. (2016). Sixth International Symposium on Bifurcations and Instabilities in Fluid Dynamics (BIFD2015): Foreword. Fluid Dynamics Research, 48(6), [061001]. https://doi.org/10.1088/0169-5983/48/6/061001

\section{General rights}

Copyright and moral rights for the publications made accessible in the public portal are retained by the authors and/or other copyright owners and it is a condition of accessing publications that users recognise and abide by the legal requirements associated with these rights.

- Users may download and print one copy of any publication from the public portal for the purpose of private study or research.

- You may not further distribute the material or use it for any profit-making activity or commercial gain

- You may freely distribute the URL identifying the publication in the public portal 


\section{Foreword \\ Sixth International Symposium on Bifurcations and Instabilities in Fluid Dynamics (BIFD2015)}

Hydrodynamic stability is of fundamental importance in fluid dynamics. As a wellestablished subject of scientific investigation, it continues to attract great interest in the fluid mechanics community. Bifurcations and instabilities are observed in all areas of fundamental and applied fluid dynamics and remain a challenge for experimental, theoretical and computational studies. Examples of prototypical hydrodynamic instabilities are the Rayleigh-Bénard, Taylor- Couette, Bénard-Marangoni, Rayleigh-Taylor, and KelvinHelmholtz instabilities. A fundamental understanding of bifurcation patterns requires the identification of mechanisms responsible for the instability. From an applied point of view, such knowledge is also necessary in order to design reliable and efficient industrial processes, such as melting, mixing, crystal growth, coating, and welding. Modeling of instability mechanisms in biological and biomedical devices is currently a very active and rapidly developing area of research with important biotechnological and medical applications, such as biofilm engineering and wound healing. The understanding of symmetry-breaking in hemodynamics could have important consequences for vascular diseases, such as atherosclerotic and vulnerable plaques, abdominal aortic aneurisms, carotid artery disease, and pulmonary embolisms and implications for vascular interventions such as grafting and stenting. The collection of papers in this issue is a selection of the presentations given at the Sixth International Symposium on Instability and Bifurcations in Fluid Dynamics (BIFD) held at the ESPCI, Paris, 15-17 July 2015. With four invited and nearly 400 contributed talks, the symposium gave an overview of the state of the art of the field including experimental, theoretical, and computational approaches to convection, effects of magnetic fields, wake flows, rotating flows, and many other problems. The complete program can be found at the conference website http://bifd2015.sciencesconf.org/.

The series of BIFD symposia began as a small workshop in Madeira, Portugal, in 2004 with just 22 participants. This number increased rapidly during the second, third, fourth and fifth symposia held in 2006 (Copenhagen, Denmark), 2009 (Nottingham, United Kingdom), 2011 (Barcelona, Spain), and 2013 (Haifa, Israel) with 40, 110, 200, and 150 participants, respectively. More than 400 participants took part in the sixth symposium in Paris from all around the world. The next symposium in the series will take place in Woodlands, Texas, USA, in July 2017 (see http://www.shsu.edu/academics/physics/ bifd-2017).

The Organizing Committee of the 6th BIFD and the BIFD Advisory Committee thank the Editors of Fluid Dynamics Research Journal for offering us the opportunity to publish a peer-reviewed special issue of the journal related to this conference. Special thanks are given to the Editor-in-Chief Professor Y Fukumoto for working closely with us on this issue. We thank both the authors and the referees for their invaluable contributions to this special issue. 


\section{P Z Bar-Yoseph}

Computational Biomechanics Laboratory, Faculty of Mechanical Engineering, Technion Israel Institute of Technology, Israel

\section{Brøns}

Department of Applied Mathematics and Computer Science, Technical University of Denmark, 2800 Kongens Lyngby, Denmark

\section{A Gelfgat}

School of Mechanical Engineering, Faculty of Engineering, Tel Aviv University, Tel Aviv 69978, Israel

\section{A Oron}

Faculty of Mechanical Engineering, Technion Israel Institute of Technology, Israel Guest Editors Fluid Dyn. Res. 46 (2014) 041001

\section{S Tuckerman}

PMMH-ESPCI, 10 rue Vauquelin, 75231 Paris Cedex 5, France

\section{J E Wesfreid}

PMMH-ESPCI, 10 rue Vauquelin, 75231 Paris Cedex 5, France

Guest editors 